\title{
PERSPECTIVAS ATUAIS DO SUS E O AGIR TECNOLÓGICO DO TRABALHADOR COMO UM ATO ÉTICO-POLÍTICO ${ }^{1}$
}

\section{Emerson Elias Merhy ${ }^{2}$}

As perspectivas atuais do SUS nos remete ao movimento político e a busca de parte de seus atores pela construção de uma sociedade pautada por uma democracia mais substantiva. Então, o SUS está envolvido, pelo menos, por esse tipo de implicação; apesar de sabermos da existência de muitas outras. Vale também entender que esse tipo de luta, no Brasil, não é só o período da luta contra a ditadura. Ele nos remete à compreensão de que na sociedade brasileira, e em particular no campo da saúde, nós já tínhamos em períodos anteriores à fase da própria ditadura disputas na sociedade brasileira, por outros formatos para as políticas de saúde e, de uma certa maneira, isso também está implicado no SUS, ou seja, o SUS é um certo arranjo no qual há esta implicação histórica.

Assim, nosso olhar deve ser remetido aos movimentos de luta contra a ditadura e pela construção de uma nova democracia e de justiça social no país, em distintos períodos, e as épocas anteriores de lutas de vários setores no campo da saúde, por outras perspectivas para o conjunto das políticas públicas na saúde. Por isso, o SUS carrega de maneira substancial estes desafios, esta perspectiva permanente em qualquer momento que a gente possa acompanhá-lo. Há momentos que a gente pode dizer que ele esteve em possibilidade de avanço mais extenso ou em momentos que a gente mesmo pode reconhecer, que do ponto de vista de conquista, de objetivos, ele pode ter sofrido retrocessos. Mas isso não rouba, dele, o conjunto dessas implicações. A implicação de pertencer a um território, que busca novos desenhos das políticas de saúde no país e a implicação de pertencer a movimentos sociais que almejam, para sociedade brasileira, uma nova democracia e uma nova justiça social.

Nesta direção, eu destacaria que sempre que nós estamos diante do SUS a gente vive tensões muito próprias destes lugares. E uma das tensões, que pra mim é relevante e

\footnotetext{
${ }^{1}$ Palestra proferida no Auditório da Faculdade de Ciências Médicas em 13/11/2003 em comemoração ao XX Ciclo de Debates do Serviço Social do Hospital das Clínicas da UNICAMP. 
que a gente vive como uma possibilidade nesses últimos anos, de uma maneira muito diferenciada entre os diferentes atores envolvidos com o SUS, é a maneira pela qual o SUS vem se apresentando, de um lado, como política pública e, de outro, como política governamental.

Esta dobra do Sistema Único de Saúde de ser, ao mesmo tempo, uma ambiciosa política pública e só se realizar enquanto política governamental, é algo que não se resolve em setores específicos das políticas, no plano do Estado, ou seja, não é algo possível de ser resolvido, pois é uma tensão constitutiva do campo político e social, no qual o SUS emerge na sociedade brasileira. E, portanto, não se resolve no campo específico de uma política. Ou ela se resolve, de uma maneira mais ampliada no campo relacional do Estado e da sociedade, ou ela praticamente não se resolve em nenhum destes lugares de sujeitos sociais e práticas. Essa é uma tensão muito presente e constante dentro do Sistema Único de Saúde, que coloca os vários atores em condições de achar, as vezes diante de certas situações, que certos aconteceres são ou não avanços.

Vou continuar insistindo na discussão da tensão constitutiva, por achá-la nuclear. Quando a gente almeja que um certo setor social torne-se um campo das políticas públicas, nós temos uma ambição de que ele respeite certas estabilidades, do ponto de vista de princípios e diretrizes, que não sejam ou não possam ser violados por grupos específicos, de ocasião, que estão operando a direção, por exemplo, de uma certa política governamental. Os atores forjadores do SUS têm isso no seu discurso. Por exemplo, quando o Sistema Único de Saúde diz que ele é acoplado a uma diretriz constitucional, na qual a saúde é um direito, na qual a saúde responde a uma construção intersetorial, na qual o Estado é responsável pelo cumprimento deste direito e na qual há a perspectiva do controle social.

Vejam que com isso estamos desenhando uma certa imagem do que significa construir e ocupar um território de políticas públicas, ou seja, um território de políticas operada no plano da sociedade, no do estado e sua maquinaria e que tem lógicas de estabilização. Qualquer que seja o formato governamental de ocasião ele não pode violar esses princípios.

\footnotetext{
2 Professor do Departamento de Medicina Preventiva e Social da Faculdade de Ciências Médicas da Universidade Estadual de Campinas.

\begin{tabular}{lllll}
\hline Serviço Social \& Saúde & Campinas & v. 3 & n. 3 & p. 1-94 Maio 2004
\end{tabular}
} 
Por exemplo, o princípio do controle social seria um dos desenhos marcadores desta característica da política pública que se ambiciona como SUS. De fato, quando a gente vivencia a construção efetiva do Sistema Único de Saúde, nestes anos todos, a gente percebe que nem sempre é tão claro o que significa o conjunto dessas diretrizes, que dão a cara do SUS como política pública. Na realidade, a gente pode dizer que se pudéssemos nos aproximar com uma lente de aumento das milhares de experiências governamentais, que ocorrem nos vários municípios do Brasil, outras dezenas de experiências governamentais que ocorrem no plano dos Estados, ou mesmo das experiências governamentais no plano nacional, em diferentes governos, nós diríamos que há uma fragilidade muito significativa nesta ambição de se ser um território de política pública, ou seja, ele ainda não conseguiu se assentar numa base social de atores que lhe dão sustentabilidade, para que possa atravessar períodos de distintos grupos governamentais que, apesar dos seus jogos de interesses, mantenham-se firmes em torno da preservação da estabilidade de alguns princípios básicos como, por exemplo, a garantia efetiva do controle social.

Na prática, hoje, não podemos dizer que no Brasil o Sistema Único de Saúde expressa uma prática de controle social efetiva. Na realidade, podemos relatar experiências e é isso que nós temos vivido no SUS, temos vividos de relatos de experiências, mais bem sucedidas, menos bem sucedidas. Revelando que o Sistema Único de Saúde tem, como uma de suas constitutividades, que ele continua sendo um campo de luta, ou seja, o Sistema Único de Saúde antes de ser efetivamente uma política pública, é um campo de disputa; e quem não perceber isso perde terreno para o outro que também disputa a direção desse território. Essa é uma das marcas que gostaria de deixar de uma maneira explícita para gente pautar um debate sobre perspectivas do SUS, hoje.

Porque, se a gente for acompanhar os vários movimentos de tentativa de construção de uma outra maquinária, para a política de saúde no Brasil, olhando para o movimento dos anos 80 e, agora, nos anos 2000, a gente percebe que certas conquistas, em alguns movimentos, são tidas como conquistas de fato e, em outros, nem tanto. E mais, para quem considera que foi um avanço, se não cuidar da construção de blocos sociais para sustentá-la, no período seguinte, elas regridem.

\begin{tabular}{lllll}
\hline Serviço Social \& Saúde & Campinas & v. 3 & n. 3 & p. 1-94 Maio 2004
\end{tabular} 
Temos vários exemplos, de políticas setoriais, na área do Sistema Único de Saúde que mostram isso. A saúde mental é uma delas. A saúde mental na realidade vive isso de forma muito intensa e permanente, e o tempo todo ela tem que mostrar, de maneira explícita, onde ela avançou, por exemplo, na luta antimanicomial. Pois, como em grande medida se apoia em experiências de governos específicos, tem que torcer para o governo não mudar. Senão ...

Isso tem muita significação, isso mostra que na realidade o projeto de construção do Sistema Único de Saúde não obedeceu, nesta situação apontada, a uma prática de acumulação social, infelizmente porque ficou reduzida às experiências governamentais. A sustentabilidade mais ampla está em outro lugar, ela não está só num conjunto de práticas governamentais, mesmo considerando que sejam, sem dúvida, fundamentais e que contribuam na construção e expressão da multiplicidade e riqueza do Sistema Único de Saúde, fazendo, deste, um processo singular e rico no mundo atual, se considerarmos as experiências de vários outros países.

Por tudo isso, temos que estar atentos para não perdermos a perspectiva de que estamos cravado em um campo de luta, como eu disse há pouco, o que pode nos fazer perder de vista que a construção da sustentabilidade exige vários movimentos. Um dos movimentos, sem dúvida nenhuma, é um movimento que sai do território da saúde, que deve ter que atingir o conjunto dos outros setores do Estado, na medida que o Sistema Único de Saúde é algo que ambiciona a sua realização num campo de reforma do Estado, ou seja, o Sistema Único de Saúde não tem como se concretizar, enquanto uma política pública, se ele não vier de mãos dadas com acumulações mais amplas, socialmente, no plano da reforma do Estado, e este é um plano no qual nós não temos tido, neste últimos anos, muitas evidências positivas.

Ao contrário, saímos da ditadura com muita ambição, ambicionamos radicalmente as práticas de reforma do Estado, apesar de termos conquistado várias coisas, vimos assistindo nos últimos anos fragilizações na consolidação desta perspectiva, como podemos ver hoje no que se refere as relações entre o público e o privado, no campo dessa reforma do Estado brasileiro.

\begin{tabular}{lllll}
\hline Serviço Social \& Saúde & Campinas & v. 3 & n. 3 & p. 1-94 Maio 2004 \\
\hline
\end{tabular} 
Na área do Sistema Único de Saúde isso tem expressões muito significativas para mostrar como que esse território é minado, como esse território ainda é muito impreciso. Por exemplo, quando a gente assiste nos últimos anos qual o conjunto de políticas, que os governos nos níveis nacional, estadual e municipal têm tido para os hospitais, a gente vai verificar isso se olhássemos dois setores hospitalares, o do hospital universitário e o dos públicos não estatais, muito significativos para a construção de um SUS mais pautado pela equidade e maior justiça social.

Iremos constatar, ao olhar com atenção para esta situação, que a política que o Sistema Único, através dos vários governos, vem construindo para esses estabelecimentos é muito desastrosa, e que pode ser traduzida da seguinte forma: quer se sustentar, privatizese! E aí a versão da privatização tem mil caras, a privatização no hospital universitário pode ser abrir uma segunda porta, terceira porta, quarta porta, quinta porta e, normalmente, fechar a primeira porta. A idéia ou o forte desejo das Misericórdias é começar a vender planos, fazer o seu "planozinho" local, para lhe dar recursos financeiros adicionais, junto com uma relação de prestadora de uma operadora de planos maior, a fim de completar o que fatura como complementar do SUS, e assim por diante. Ou seja, a política da reforma mais ampla do Estado público e do lugar do privado, no Brasil, não vem sinergicamente apontando para uma perspectiva de sustentabilidade de certos setores fundamentais para nossa aposta de construção de um Sistema Único de Saúde mais democrático e mais justo. Não podemos nos sentir tranqüilo com tudo isso.

Ao contrário, este front necessário de disputa opera em um território de muita fragilidade. Então, isso exige de nós o entendimento profundo de como é frágil a consolidação do Sistema Único de Saúde, enquanto uma política pública mais estável, que sofre variações conjunturais significativas e que exige dos seus militantes atenção permanente e costuras ampliadoras. Ele é uma construção muito delicada porque ainda não atingiu um patamar de institucionalização, que lhe permitisse poder ultrapassar certos períodos com maior tranqüilidade.

Além dessa temática, há que se levar em conta um outro aspecto mais específico do próprio território da saúde e que não é também um território consolidado, do ponto de vista da construção de uma política pública, que nos dê tranqüilidade. Este aspecto nos

\begin{tabular}{lllll}
\hline Serviço Social \& Saúde & Campinas & v. 3 & n. 3 & p. 1-94 Maio 2004
\end{tabular}


remete a especificidade do território da saúde, que é a opção pela construção de certas modalidades de produção do cuidado para o usuário, individual e coletivo, à qual o Sistema Único adere.

Aqui, estou me remetendo a aquilo que é mais próprio do campo da saúde. Ou seja, quando a gente fala em campo da saúde, em tudo isso que eu disse sobre a reforma do Estado, o público e o privado, dentro de algo que é singular, que tem marca substancial que o diferencia dos outros lugares, há que se ter sempre claro, o que e quem realiza o conjunto das práticas sociais demarcadoras deste campo. Afinal de contas, este campo da saúde é lugar do quê?

É lugar da construção de intervenções tecnológicas cuja alma, cujo sentido, é a produção do cuidado em saúde, que tenta responder ao que socialmente se constitui e se denomina mundo das necessidades de saúde dos indivíduos e dos coletivos. Então, isso é que dá marca e é propriedade deste campo; aí, ele se diferencia, por exemplo, do campo educacional ou de um outro campo social, como o das práticas religiosas. Na realidade, o conjunto de práticas sociais, cuja alma é o campo da saúde, está implicada com esse tipo de questão. Elas são práticas reconhecidas e produzidas, neste momento, pela sociedade, como portadoras de capacidades tecnológicas para responder às necessidades de saúde e seu complexo mundo.

Este, também, é um lugar de intensas disputas. De disputas que fazem referência a nós, trabalhadores de saúde, no nosso dia a dia. Para nós vivenciarmos, de um modo muito próximo, o tema que eu falei da reforma do Estado, e do público e do privado, nós temos que se confrontar com uma situação imediata de conflito, nessa área, que tenha sentido no nosso cotidiano ou, o que nos sobra é abstrair, do ponto de vista do pensamento e da militância, a temática da reforma do Estado. Mas, esse outro lado, que o Sistema Único de Saúde está envolvido e está amarrado, que lhe dá substância, esse se faz presente no nosso dia a dia e a nós se refere. Pois, estar implicado com a produção do cuidado em saúde é o nosso lugar, nós trabalhadores de saúde vivemos isso. Somos considerados trabalhadores de saúde, e não de outra coisa qualquer, porque somos um conjunto de sabidos singular, que estamos neste campo da saúde por sermos sabidos de processos de ações tecnológicas que respondem ao mundo das necessidades de saúde. E, neste lugar, 
estamos amarrados a certas modalidades de se fazer isso, de certas maneiras de se realizar isso. E, neste território, fazemos parte das disputas que o campo contém e que é muita intensa.

É um território que coloca em confronto o conjunto dos próprios trabalhadores de saúde e, que na realidade, nos remete a opções, que enquanto trabalhadores temos que ter, implicando na nossa defesa de certas perspectivas para a construção do Sistema Único de Saúde, e queiramos ou não, aí somos militantes cotidianos. Esse talvez seja o lugar pelo qual nós trabalhadores de saúde, na nossa militância cotidiana, com o nosso "saber ser" trabalhador de saúde, podemos nos tornar sujeitos políticos militantes de um Sistema Único de Saúde mais eqüitativo, mais resolutivo, mais voltado para a vida do usuário. Nós não precisamos nos descolar do cotidiano para militar, ao contrário, é aí, no nosso próprio lugar de trabalhador, que agimos politicamente. Temos que nos manter neste lugar e politizá-lo de uma certa maneira, e que não é a politização enquanto a constituição de uma certa organização política, mas é a politização enquanto a adoção de certas opções, do ponto de vista ético e tecnológico, do nosso lugar e do nosso fazer que mexe com a forma social de se construir vidas.

E neste lugar, na nossa opção ético-tecnológica do nosso lugar e do nosso fazer, nós, como sujeitos políticos, podemos avolumar a capacidade de acumular na direção de um Sistema Único, que consiga ter mais sinergia com tudo isso que eu coloquei. Ou, não.

Eu diria que no cotidiano, o conjunto dos atores sociais mais importantes para a construção das ações de saúde, no plano do Sistema Único de Saúde, os que identifico como os mais expressivos, são: os governantes de ocasião, os dirigente de ocasião, os trabalhadores de saúde, os usuários dos serviços e os empresários do setor. Diria que desse conjunto, desta rede de atores, os trabalhadores de saúde são os que mais detém potências de "auto-poder", conservador ou progressista - que lhes dão graus significativos de liberdade para agir no cotidiano, que não precisam pedir muita licença a outros para construir a sua ação junto do mundo das necessidades -, de intervir na construção de um Sistema Único mais justo e democrático.

\begin{tabular}{lllll}
\hline Serviço Social \& Saúde & Campinas & v. 3 & n. 3 & p. 1-94 Maio 2004 \\
\hline
\end{tabular} 
Isto traz uma implicação que tem que nos inquietar. Tem que nos deixar, absolutamente, preocupados - no bom ou no mau sentido - e isso depende de cada um, não tenho receita. Mas, que tem que nos deixar preocupados, tem.

Por quê?

Porque se somos, como se fatos somos, enquanto trabalhadores, atores fundamentais é porque está em nós muitas das perspectivas de construção de um Sistema Único diferenciado, que a gente pode desejar. Isto é, muito depende da gente mesmo, ou seja, depende da nossa capacidade de ação, do ponto de vista tecnológico, como alguém que faz uma opção ético-política, no cotidiano; alguém que faz uma opção por entender que o encontro, entre o nosso agir tecnológico e o mundo das necessidades, é um agir tecnológico e, como tal, é um ato político.

Em que sentido ele é um ato político? Ele é um ato político porque ele implica uma opção social, assumida por nós trabalhadores, se militamos a favor da vida, ou não, ou, até, se militamos a favor de uma morte menos sofrida. No campo da saúde, qualquer que seja a imagem das necessidades de saúde, ela sempre nos remete à seguinte expressão: nós estamos falando de algo que nos interessa muito, que é o modo pelo qual podemos viver a nossa vida.

Assim, traduziria que o mundo das necessidades de saúde, para cada um de nós ou para os coletivos, representa um conjunto de situações que sempre remete a possibilidade de vivermos a nossa vida, dentro do nosso modo de vive-la, ou seja, sem que isso seja um fenômeno idêntico a outro modo. Nós temos capacidade de representação, temos possibilidades de nos sentirmos alegres ou tristes, enquanto indivíduos ou coletivos, de maneiras diferenciadas, nós temos diferenças para compreender o que são obstáculos para o viver a nossa vida; e, portanto, nessas diferenças os grupos sociais e os indivíduos, também expressam de maneira diferenciada o que são as necessidades, para si. Isso constitui essa riqueza que é o conjunto das necessidades sociais. Mas, de uma certa maneira a todos nós indivíduos ou coletivos remete a imagem de que estamos falando de viver vidas. Ora viver vidas é uma porta para ver que vida produz mais vida e, dentro disso, podemos optar para que nosso ato vivo não produza ou não contribua para produzir mais morte.

\begin{tabular}{lllll}
\hline Serviço Social \& Saúde & Campinas & v. 3 & n. 3 & p. 1-94 Maio 2004
\end{tabular} 
Esse pode ser um dos nossos objetos, e toma-lo como tal é um ato político. É um ato político porque nós coloca no nosso agir tecnológico opções, como: indivíduos ou coletivos, profissionais, trabalhadores de estabelecimentos de saúde; como alguém que se sabendo portador de uma arma política na mão, com o seu fazer, faz uma opção na forma de usar o seu saber tecnológico. Alguém que aponta esta arma para que a vida produza mais vida, e não para que a vida produza mais morte, como o modelo dominante, médicohegemônico, muitas vezes pratica.

Essa opção não está dada, automaticamente, ela é uma opção que nós fazemos no cotidiano entre nós, que nós fazemos no cotidiano com o usuário, que nós fazemos no cotidiano com o nosso trabalho. Se não tivermos esta percepção, a gente abandona algo que é fundamental para essa decisão, que é nos compreendermos como sujeitos políticos desse ato e em ato.

No modelo, mais corriqueiro praticado, nós não nos implicamos muitas vezes com os nossos atos, que produzem mortes - e, olha, que são muitos os trabalhadores de saúde que produzem morte e que não se implicam e nem se responsabilizam com isso -, e ao fazermos isso, na realidade estamos nos implicando e se responsabilizando, também, como sujeitos políticos, mas como sujeitos que fazem a opção ético-política por uma militância de negação de um Sistema Único de Saúde mais democrático, justo e construtor da equidade social no direito a uma vida mais qualificada.

Nesta direção, creio que essa é uma das grandes potências que nós temos na mão, que é essa nossa implicação na ação tecnológica, apontando para uma vida que ambiciona ser mais vida. Mas, também me remeto à perspectiva de podermos morrer de modo mais alegre, e aí lembro de um filósofo do século XVI, que é o Espinosa, que dizia que "a alegria é uma manifestação do viver”, e de quem faço uso um pouco enviesada, pois vou falar de uma outra coisa. Nós podemos, além de produzir mais vida, produzir modos de morrer mais alegres na nossa sociedade, ou seja, morrer não precisa ser a desgraça que é, e nós não fazemos isso, nós praticamente perdemos ligações com outros humanos muitos anteriores a nós, que construíram ritualísticas com a morte muito mais saudáveis.

Acho que isso faz parte da nossa opção também como sujeito político no cotidiano, nós temos que nos preocupar com isto, e nesta direção para ir mais ou menos 
fechando a minha intervenção, eu gostaria de colocar o quanto isso traz para nós responsabilidades. Por quê?

Porque na realidade, nós no cotidiano não temos essa compreensão de maneira coletiva, nem de uma forma muita intensa. Normalmente nós nos posicionamos como vítimas do cotidiano e não como sujeitos do cotidiano, ou seja, nós nos posicionamos como vítimas dos outros atores políticos, dos outros sujeitos políticos e não nos vemos como vítimas de nós mesmos. E, na realidade, eu gostaria de inverter esse olhar, gostaria de dizer que na realidade nós nos vemos como vítima dos outros, porque somos vítimas de nós mesmos, porque não nós reconhecemos como sujeitos políticos, que fazem opções éticotecnológicas, no seu trabalhar cotidiano, em todos os lugares onde estamos atuando, inclusive enquanto trabalhador.

Acho que esta é uma questão nuclear do Sistema Único de Saúde, hoje. Por quê? Porque se eu puder fazer um desenho de onde o Sistema Único de Saúde mais acumulou, nestes anos todos da Constituição para cá, ou até pré-constituição, pois já era uma aposta perseguida por muitos antes da própria Constituição; se puder ver este desenho, vou verificar que o Sistema Único de Saúde até que avançou razoavelmente na sua lógica institucional jurídico-político, ou seja, na questão da municipalização, na conquista, até consolidada, do ponto de vista de lei. Do ponto de vista de lei o controle social está escrito, do ponto de vista da lei há a representação do conjunto de atores sociais nos espaços políticos de decisão, a existência das conferências estão escritas e têm que ser cumpridas, do ponto de vista de arranjos até financeiro do setor há uma certa consolidação (apesar da persistência forte do modo inampisado de financiar ações de saúde). De todos setores da maquinaria social, os setores da saúde e educação são os que têm mais se consolidado. É só ver a recente agressão que a saúde sofreu de retirada de perto de cinco bilhões, do seu orçamento, e o recuo do governo. Isso mostra que, do ponto de vista da lógica de institucionalização, o Sistema Único de Saúde tem avanços na construção da sua maquinária, no reconhecimento do lugar do gestor, nos encontros dos gestores, na construção das mesas de negociação.

Mas se nós fôssemos ver, apesar disso tudo, onde ele menos avançou, veremos que é nesse território da implicação do trabalhador de saúde, e que faz referência ao tema

\begin{tabular}{lllll}
\hline Serviço Social \& Saúde & Campinas & v. 3 & n. 3 & p. 1-94 Maio 2004 \\
\hline
\end{tabular}


da sustentabilidade que tratei no começo da minha fala. Esse é um dos lugares mais frágeis do Sistema Único de Saúde, por dentro. É o lugar no qual o conjunto dos trabalhadores ainda não se posicionaram como sujeitos políticos ampliados, pois como regra eles tem se posicionado como sujeitos políticos corporativos.

Isso é um grande problema do Sistema Único de Saúde, o fato da gente ter milhares e milhares de forças sociais envolvidas na construção desse cotidiano, e nós trabalhadores de saúde ainda não termos nos constituído e nos reconhecido como sujeitos políticos de construção e consolidação do SUS enquanto uma política pública. Este é um dos grandes calcanhares de Aquiles daquela dobra da política pública e da política governamental, que eu tinha apresentado para vocês.

De um lado, temos uma fragilidade do que diríamos ser o lugar da macropolítica, que é o campo da reforma do Estado, e de outro lado, temos uma grande fragilidade que é a nossa ação do cotidiano, que é o lugar da micropolítica, lugar no qual enquanto sujeitos construtores de novas formas de produção da saúde, no Brasil, somos um dos principais protagonistas. E, isso faz referência a todos nós como trabalhadores sujeitos políticos, e não a nós enquanto corporações profissionais.

Temos assistido retrocessos nesse caminho. É só mirarmos na grande discussão sobre o ato médico, que a minha categoria profissional, hegemonizada pelo seu lado mais conservador, trava como bandeira de luta hoje no Brasil; que é uma bandeira de luta que se vitoriosa será destruidora do Sistema Único de Saúde. Tenho podido colocar isso em nível nacional, já escrevi sobre isso, e não perco a oportunidade de falar de que a vitória da lei do ato médico, defendida pelas entidades médicas, é anti-SUS. E, por isso, ela tem que ser um problema para os outros trabalhadores. Acho, inclusive, que os outros trabalhadores têm reagido ao ato médico de uma maneira atrasada, tão atrasada quanto a própria proposta de parte dos médicos, que é a de se posicionar também como corporação, que se auto afirma, e neste caminho, a idéia nuclear de sermos sujeitos políticos da produção da vida e de um morrer mais alegre fica secundarizada, quando, realmente, do meu ponto de vista, ela é a grande alma do nosso negócio: produzir saúde.

Obrigado!

\begin{tabular}{lllll}
\hline Serviço Social \& Saúde & Campinas & v. 3 & n. 3 & p. 1-94 Maio 2004 \\
\hline
\end{tabular} 
